\title{
Methadone replacement therapy: tried, tested, effective?
}

\author{
${ }^{1} \mathrm{JR}$ Robertson, ${ }^{2} \mathrm{AM}$ Daniels \\ ${ }^{1}$ General Practitioner, Muirhouse Medical Group and Clinical Reader, University of Edinburgh, Scotland, UK; ${ }^{2}$ Consultant Psychiatrist \\ (retired), West Midlands Poisons Unit, City Hospital, Birmingham and Honorary Research Fellow, School of Health and Population Sciences, \\ University of Birmingham, UK
}

\begin{abstract}
Methadone prescription is a controversial topic. While many believe that it is an effective treatment for opiate dependency, others argue that it is not successful in reducing either the addiction or even injecting behaviour. In this debate, Dr Robertson makes the case that methadone has been well tested, is cheap and acceptable to the patient and results in visible improvement. Dr Daniels argues that methadone treatment is philosophically ill-conceived, ethically dubious, and costly. He also highlights evidence that the treatment is potentially harmful to both patients and those in contact with them.
\end{abstract}

Correspondence to R Robertson, Muirhouse Medical Group, I Muirhouse Avenue, Edinburgh EH4 4PL, UK

tel. +44 (0) I 3 I 3322984 e-mail Roy.Robertson@ed.ac.uk

Correspondence to AM Daniels, e-mail adan2II530@aol.com

KEYWORDS Substance abuse, methadone, injections, heroin, narcotics, opioids

DECLARATION OF INTERESTS No conflicts of interest declared.

\section{Methadone replacement therapy: tried, tested and effective}

\section{R Robertson}

Methadone is an effective treatment for opiate dependency. Social disapproval and the potential risks should not be barriers to providing this much needed treatment. Diseases such as AIDS, anthrax, gangrene, hepatitis and cachexia from self-neglect are common and the reappearance of miliary tuberculosis, the increase in serious deep vein thrombosis and the need for disfiguring surgery and amputations make drug use a reservoir of pathology which will continue to cost individuals and healthcare organisations dearly. ${ }^{1-4}$ There is little alternative to methadone and opiate substitution treatment (OST) in the prevention and treatment armamentarium, apart from more intensive OST with heroin, ${ }^{5-6}$ and this should be supported with enthusiasm and commitment.

Medical treatments are no stranger to controversy. Emotions run high when the issue is survival, relief of pain and the possibility, however remote, of curing a condition which causes suffering. For many reasons the treatment of drug users is among the most contentious social topics. The most obvious issues adding fuel to the debate are the illegal aspects inherent in the use of opiate drugs, the impact on children and extended families of drug use and the resulting damaging consequences of violence, criminality and sudden death. The cost to individuals and society is high.

It is strange therefore that a highly effective treatment for opiate users is subject to controversy. Treatment with methadone is demonised and scrutinised in a way not common to other medical interventions. Perhaps this is an extension of the 'Cinderella' status of mental health problems with the additional stigma of criminal behaviour and the inevitable, almost medieval, fear of the effects of drugs and their apparent uncontrollable addictive qualities.

Medical practitioners, however, are scientists and therefore have an obligation to treat illness with the most effective remedies available and a further responsibility to act without prejudice, bias and regardless of personal opinion. Treatment must be researched, programmes audited and the results compared to best practice as presented in the international literature. While subject to the wider political, social and economic pressures, the fundamental business of medicine is caring for those suffering and managing the medical consequences of damaging behaviour, however reckless. Passing judgement on irresponsible behaviour is not appropriate, whether it is skiing, riding a motorcycle, climbing an impossible cliff or misuse of alcohol or opiates. To withhold treatment or to fail to maximise efforts to encourage individuals to access treatment services should be regarded as criminal and professional neglect, similar to withholding treatment for any other disorder. For some reason, neglect in this area of medicine and denial of the condition as a treatable disorder seem to be exempt from professional reproach.

Methadone is an effective treatment for opiate dependency. Moreover the evidence supporting treatment for dependency is as substantial as that available for the treatment of most serious disorders, including other 
fatal conditions such as cancer, heart disease and infectious disease. Any doubt that opiate drug taking, especially by injection, is frequently fatal is easily countered by the weight of research into blood-borne virus infection, overdose, bacterial infections and a growing collection of conditions directly related to drug taking. Hepatitis, AIDS, anthrax, sudden death from overdose, septicaemia, endocarditis, mental distress leading to suicide and personal neglect are all commonly found in the national statistics of most countries.

It is ironic therefore that a treatment which is readily available receives such harsh criticism; a treatment that has been well tested over many decades, is cheap and acceptable to the patient, results in visible improvement within days of starting and with an ongoing efficacy which can return individuals from a parlous, isolated and distressed state to one of normality, calm and productivity. Methadone (and other opiate drugs such as buprenorphine, morphine, other codeine derivatives and heroin on prescription used as alternatives to illegal opiates) is literally a lifesaving intervention with potential beyond the impact on individuals. It can prevent epidemics of blood-borne virus infections, normalise behaviour, prevent criminality and save the costs of judicial and custodial consequences. If such a treatment was available for alcohol abuse or other chronic relapsing disorders it would no doubt have an even bigger impact. Methadone is on a parallel with insulin in medical pharmacopoeia in two ways: its lifesaving potential and its efficacy over a lifetime. Both diabetes and opiate dependency are for most individuals a lifelong problem requiring chronic disease management. Methadone is widely prescribed in many countries following successful trials over many years. ${ }^{7-9}$ Methadone and other opiates used as a medically prescribed substitute for illegal heroin are known collectively as Opiate Substitution Treatment (OST).

Evidence supporting OST comes in many forms and the Cochrane database categorises the value of this research which ranges from randomised controlled trials to personal testimony and case reports. Cohort studies and randomised controlled trials of OST have been done repeatedly in many countries and evidence from these, along with personal testimony and numerous anecdotes from doctors, nurses and families are also readily available. ${ }^{10-12}$ Organisations such as the National Institute for Health and Clinical Excellence (NICE) and the Scottish Intercollegiate Governance Network (SIGN) have also undertaken research into the efficacy of OST. ${ }^{13-15}$ NICE for example carried out several investigations into methadone use, finding it effective in longterm use and defining the characteristics of treatment packages which provide maximum benefit. Perhaps more convincing than anything is the evidence that prescribing agencies are well used. Opiate users attend for treatment when opiate substitutes are delivered, and they do this consistently over many years. If we believe in patient choice, then this success is a clear message.

So where do the anxieties, criticisms and, at times, hostility to OST treatments come from? This form of treatment is frequently seen as a failure to allow recovery, at best a substitute for the proper process of helping the individual to achieve a state of abstinence and at worse a reckless and lazy intervention full of dangers greater than the initial state of addiction. Opiate Substitution Treatment is not without complications and like all treatments, falls short of perfection. When used inappropriately or with-out regard for side-effects and complications, these strong opiates are dangerous. Casualties occur either from overdose from the prescribed drug or, more often, from a combination of prescribed and illegally acquired drugs. Given these shortfalls it is not difficult to see why concerns are raised. The stakes are high and the people receiving treatment are those who are living in stressed and marginalised situations where multiple problems conspire to make the risk of serious harm high. Careful study of these risks have identified the dangers of OST to be highest in those starting treatment and to be considerably less in those in a steady state of long-term treatment often referred to as 'maintenance'. Risks are increased when tolerance is lost, after admission to custody or after detoxification in hospital, and deaths sadly still occur from improper or coercive detoxification. ${ }^{16-18}$

These potential risks are clearly outweighed by the advantages and protective effect of OST. Evidence is fortunately available in large quantities. In particular, studies have shown that OST protects against death from opiate use, reduces criminality and draws individuals into contact with support agencies that deliver a range of other services. ${ }^{19-22}$

Further assessment of OST must compare it to alternative interventions. As might be expected, comparisons of this sort have been tried and tested. Throughout the 1970s naturalistic trials of no treatment with OST resulted in clusters and epidemics of bloodborne viruses and overdose deaths. ${ }^{23,24}$ Trials of OST versus no treatment have clearly shown a rising death rate in the placebo group (a study which must surely be ethically suspect when others have shown the benefit of OST). ${ }^{25}$ Throughout the 1990s several trials indicated that methadone treatment had previously been of relatively poor quality. Evidence was found that demonstrated the current level of dose was inadequate. These studies re-emphasised the finding that doses of $80 \mathrm{mg}$ to $100 \mathrm{mg}$ per day had a superior effect in preventing relapse and in achieving the other beneficial outcomes of OST. ${ }^{26}$ Consequently, national guidelines focused on techniques for safe induction into methadone therapy and rapid titration to achieve therapeutic blood levels. ${ }^{27}$ 
Other trials designed to compare methadone treatment with opiate-free treatment programmes have been difficult or impossible to establish as randomisation into a prescribed treatment and a non-prescribing therapy is almost impossible to design. Comparisons of these two approaches therefore depend upon observational studies of cohorts receiving different treatments. Results are inconclusive as both treatments show evidence of improvement, depending upon the quality of the services provided. Measurements and outcomes are difficult to standardise and follow-up over a reasonably prolonged period has been shown to be difficult. ${ }^{28}$ Evidence from cohort studies of patients taking OST is more robust than from detoxification treatments or from residential rehabilitation. ${ }^{18}$ Although proponents of detoxification might argue that this is because those graduating from an abstinence-based therapy are less visible to observation, the figures themselves indicate the failure of these treatment packages in the majority who have relapsed into illegal drug use or returned to an OST agency.

Debate about OST and in particular methadone should not revolve around the perceived risks and dangers; these are present in many medical interventions. The key issue should be the safest way to manage the maximum number of individuals in a therapeutic setting. Treatment for life-threatening conditions is always challenging. The risk of dying from any surgical treatment is significant. There are no guarantees that chemotherapy for malignant disease for example is risk-free and it is widely accepted that admission to hospital is, for the elderly and immune compromised, a potentially lethal event. In all these situations, care and expense is expended to minimise the risks and to protect patients from the potential side-effects of treatment. Similar contingencies are needed in methadone programmes and expense should not be spared in maximising efficacy and safety. Similarly research and audit of methadone treatments should continue. Investigations into cardiotoxic sideeffects (a hazard shared, but not widely publicised, with many other drugs such as the atypical antipsychotics, disulfiram and some antidepressant medications) should also continue.

One of the serious unintended consequences of criticism of methadone is poor adherence and compliance with treatment. This problem is also found with other conditions. A study showed for example that fifty per cent of patients with schizophrenia stopped treatment against advice because of the negative connotations attached to mental illness. ${ }^{29}$ Negative portrayal of OST results in considerable loss of opportunities to engage people who need treatment. Many addicted patients for example resist treatment due to misguided negative beliefs about the dangers of OST. They believe that it is dangerous, that prolonged treatment is inevitable and that there are a number of side-effects attributed to the drug, including erosion of bones and teeth, damage to the liver, distortion of cognition, persistent addiction and a belief that withdrawal from the drug is impossible. Negative attitudes about methadone treatment also come from another disturbing source. Drug dependency is closely associated with the criminal justice system, which means that surveillance, coercive interventions and at times custodial periods result in imposed targets for reduction, legal constraints (drug treatment orders) and penalties for persisting in treatment and failing to achieve a drug-free state (a dangerous approach not supported by evidence). There is also an often denied but frequently reported pressure put on pregnant women and their partners to reduce treatment, the cost of non-compliance being the threat of removal of the baby or child from the custody of its parent(s).

Opiate users are neglected by society and the caring professions to the extent that some would call them a victimised minority group. Those who witness the depraved state of the chaotically addicted opiate user see parallels with a Dickensian level of poverty and the resulting medical conditions, often in advanced states, rarely seen in Western countries. The opportunity to stop damaging behaviour, prevent AIDS and other blood-borne virus epidemics and bacterial infections and to return a patient to a state of health and autonomy is one of the rare opportunities for healthcare workers to provide a life-saving intervention and a safer environment for us all.

\section{REFERENCES}

I Strathdee SA, Hallett TB, Bobrova $N$ et al. HIV and risk environment for injecting drug users: the past, present, and future. Lancet 2010; 376:268-84. http://dx.doi.org/l0.1016/SOI406736(10)60743-X

2 Health Protection Scotland, NHS Scotland. An outbreak of anthrax among drug users in Scotland December 2009 to December 2010. A report on behalf of the National Anthrax Outbreak Control Team [Internet]. Glasgow: HPS and NHS Scotland; 2012 [cited 2012 April 4]. Available from: http://www.documents.hps.scot.nhs.uk/ giz/anthrax-outbreak/anthrax-outbreak-report-20I I-I2.pdf

3 Nelson PK, Mathers BM, Cowie B et al. Global epidemiology of hepatitis B and hepatitis $C$ in people who inject drugs: results of systematic reviews. Lancet 2011; 378:57I-83. http://dx.doi. org/I0.1016/S0I40-6736(II)6I097-0

4 Hutchinson SJ, Roy KM, Wadd S et al. Hepatitis virus infection in Scotland: epidemiological review and public health challenges. Scott Med J 2006; $51: 8-15$. http://dx.doi.org/I0.1258/rsmsmj.5I.2.8

5 Oviedo-Joekes E, Brissette S, Marsh DC et al. Diacetylmorphine versus methadone for the treatment of opioid addiction. $N$ Engl J Med 2009; 36I:777-86. http://dx.doi.org/I0.1056/NEJMoa08I0635

6 Strang J, Metrebian N, Lintzeris $\mathrm{N}$ et al. Supervised injectable heroin or injectable methadone versus optimised oral methadone as treatment for chronic heroin addicts in England after persistent failure in orthodox treatment (RIOTT): a randomised trial. Lancet 2010; 375: I885-95. http://dx.doi.org//0.I0I6/S0|40-6736(I0)60349-2

7 Dole VP, Robinson JW, Orraca J et al. Methadone treatment of randomly selected criminal addicts. N Engl JMed 1969; 280; |372-5. http://dx.doi.org/I0.1056/NEJMI96906/92802502

8 Dole VP, Nyswander M. Rehabilitation of patients on methadone programs. Proceedings of the 5th National Conference on Methadone Treatment. New York: National Association for the Prevention of Addiction; 1973. 
9 Ball JC, Ross A. The effectiveness of methadone maintenance treatment: patients, programs, services and outcomes. New York: Springer-Verlag; I991. http://dx.doi.org// 0.1007/978-I-46/3-9089-3

10 Gossop M, Marsden J, Stewart D et al.The National Treatment Outcome Research Study (NTORS): 4-5 year follow-up results. Addiction 2003; 98:29I-303. http://dx.doi.org/I0.1046/j.I360-0443.2003.00296.x

I I Gossop M, Stewart D, Browne $\mathrm{N}$ et al. Methadone treatment for opiate dependent patients in general practice and specialist clinic settings: outcomes at 2-year follow-up. J Subst Abuse Treat 2003; 24:3 I 3-2I. http://dx.doi.org/I0.1016/S0740-5472(03)00040-0

12 Bell J. Delivering effective methadone treatment. In: Ward J Mattick RP, Hall W, editors. Methadone maintenance treatment and other opioid replacement therapies. Amsterdam: Harwood Academic Publishers; 1998.

I3 National Institute for Health and Clinical Excellence (NICE). Methadone and buprenorphine for the management of opioid dependence. NICE technology appraisal guidance I/4 [Internet]. London: NICE; 1997 [cited 2012 April 4]. Available from: http:// www.nice.org.uk/guidance/TAI I4

14 National Institute for Health and Clinical Excellence (NICE). Drug misuse: psychosocial interventions [Internet]. London: NICE; 2007 [cited 20I2 April 4]. Available from: http://www.nice.org.uk/CG5I

15 Scottish Intercolllegiate College Network (SIGN). Management of hepatitis C.A national clinical guideline [Internet]. Edinburgh: SIGN 2006 [cited 2012 April 4]. Available from: http://www.sign.ac.uk/ pdf/sign92.pdf

16 Clausen T, Anchersen K, Waal H. Mortality prior to, during and after opioid maintenance treatment (OMT); a national, prospective cross-registry study. Drug Alcohol Depend 2008; 94:15I-7. http:// dx.doi.org/I0.1016/j.drugalcdep.2007.II.003

17 Davoli M, Bargagli AM, Perucci CA et al. Risk of fatal overdose during and after specialist drug treatment: the VEdeTTE study, a national multi-site prospective cohort study. Addiction 2007; I02:1954-9. http://dx.doi.org//0.I I I I/j. I360-0443.2007.02025.x

18 Kimber J, Copeland L, Hickman M et al. Survival and cessation in injecting drug users: prospective observational study of outcomes and effect of opiate substitution treatment. BMJ 2010; 341:c3172. http://dx.doi.org//0.II36/bmj.c3 I72

19 De Maeyer J, Vanderplasschen W, Camfield L et al. A good quality of life under the influence of methadone: a qualitative study among opiate-dependent individuals. Int J Nurs Stud 20II; 48:1244-57. http://dx.doi.org/l0.1016/j.ijnurstu.201 I.03.009
20 Mattick RP, Breen C, Kimber J et al. Methadone maintenance therapy versus no opioid replacement therapy for opioid dependence. Cochrane Database Syst Rev 2009; 3:CD002209.

21 Robins LN. The Sixth Thomas James Okey Memorial Lecture. Vietnam veterans' rapid recovery from heroin addiction: a fluke, or normal expectation? Addiction 1993; 88:104I-54. http://dx.doi. org/I0.I I I I/j.I360-0443.1993.tb02 I23.x

22 Reno RR, Aiken LS. Life activities and life quality of heroin addicts in and out of methadone treatment. Int J Addict I 993; 28:2 I I-32.

23 Robertson JR, Bucknall AB, Welsby PD et al. Epidemic of AIDSrelated virus (HTLV-III/LAV) infection among intravenous drug abusers. Br Med J 1986; 292:527-9. http://dx.doi.org//0.II36/ bmj.292.6519.527

24 Bewley T. Recent changes in the pattern of drug abuse in the United Kingdom. Bull Narcot 1966; I8:I-13.

25 Gunne LM, Grondbladh L. The Swedish methadone maintenance program: a controlled study. Drug Alcohol Depend 1981; 7:249-56. http://dx.doi.org/I0.10I6/0376-87I6(8I)90096-X

26 McGlothlin WH, Anglin MD. Long-term follow-up of clients of high- and low-dose methadone programs. Arch Gen Psychiatry 1981; 38: I055-63. http://dx.doi.org/I0.100 I/archpsyc. I98I.01780340I070I3

27 Department of Health (England) and the devolved administrations. Drug misuse and dependence: UK guidelines on clinical management [Internet]. London: Department of Health (England), the Scottish Government and Northern Ireland Executive; 2007 [cited 2012 April 4]. Available from: http://www.nta.nhs.uk/uploads/clinical_ guidelines_2007.pdf

28 Amato L, Minozzi S, Davoli M et al. Psychosocial combined with agonist maintenance treatments versus agonist maintenance treatments alone for treatment of opioid dependence. Cochrane Database Syst Rev 20I I; 10:CD004I47.

29 Scottish Intercollegiate Network (SIGN). Psychosocial intervention in the management of schizophrenia [Internet]. Edinburgh: SIGN; 1998 [cited 2012 April 4]. Available from: http://www.sign.ac.uk/ pdf/sign30.pdf

\section{Methadone replacement therapy: tried, tested and ineffective}

\section{AM Daniels}

Addiction to opiates is a problem that has increased in the UK at an alarming rate in the last fifty years. According to an editorial in The Times newspaper (14 June, 1955) there were approximately 48 known heroin addicts in Britain. In 1961, Lord Brain was confident in writing:

After careful examination of all the data put before us we are of the opinion that in Great Britain the incidence of addiction to dangerous drugs - which today comprise not only morphine and heroin but also such other substances coming within the provisions of the Dangerous Drugs Act, 195I, as pethidine, methadone, levorphanol, etc. - is still very small.

Four years later, the same committee reported that, though the number of addicts had risen, it was still very small. The number of known injecting heroin addicts in
1959 was 64 , but by 1964 it was $342 .^{2}$ There had also been a marked change in the age distribution of those addicted to 'dangerous drugs.' In 1959 only II per cent had been under the age of 35; by 1964, 40 per cent were. $^{3}$ Clearly, addiction to drugs was becoming a problem of the young.

According to current estimates, there are now 103,185 injecting opiate addicts and 160,887 non-injecting opiate 'users' in the UK. ${ }^{2}$ Even allowing for possible underestimation of the numbers in the late 1950s and 60s, this is a very startling increase.

Other such noticeable increases in drug addiction have been known to occur, for example among American soldiers serving in Vietnam. Robins found that up to 20 per cent of returning veterans were at some time in 
their tours of duty addicted to heroin. ${ }^{3}$ A large and comparatively swift increase in a certain type of behaviour however does not signify an epidemic in the medical sense. The use of mobile phones would not be considered an epidemic disease even if such use caused an increase in brain tumours. But it is easy to confuse conduct that leads to disease with disease itself. Indeed, the disease concept of addiction has come under strong, and in my opinion justified, attack from philosophers and philosophically-informed psychologists. ${ }^{46}$ According to these authors, doctors and others often overlook crucial facts that contradict, undermine and invalidate the disease concept of addiction. American servicemen who served in Vietnam for example recovered quickly from addiction to heroin without any medical or other intervention, to the extent that after three years, their rate of addiction was no higher than that of draftees who were called up to go to Vietnam but did not do so because of the end of the war.

If the disease concept is mistaken, it is not surprising that the results of attempts to treat heroin addiction as if it were an illness are at best equivocal. The primary purpose of drug addiction 'treatment' should surely be the return of patients to a drug-free existence; a secondary goal might be harm reduction, though this goal is not without its ethical problems. ${ }^{8}$ The prescription of methadone does not reduce the length of either addiction or even of injecting behaviour. According to one long-term follow-up study of 655 patients in Scotland, of whom 557 had received opiate substitution therapy (OST), such 'treatment was inversely related to the chances of achieving long term cessation [of injection]'. ${ }^{9}$ Kimber et al. claimed that the prescription of methadone increased overall survival, although 45 per cent of the 228 patients who died in the period of follow-up did so from blood-borne viruses whose date of acquisition is not known, and therefore the conclusion is at best optimistic. Moreover, 55 of the patients who died did so from an overdose of drugs. Assuming that they died of opiate-poisoning, which is likely, and that the pattern of such poisoning among them reflected the pattern of opiate poisoning in Scotland as a whole (in 2010 there were 254 deaths associated with heroin and 174 with methadone $)^{10} 22$ of the 55 patients would have died of a 'methadone-associated' death, that is to say, a death in which methadone was probably a necessary but perhaps not a sufficient cause of death.

In the UK it is known that because distribution of the drug is not without leakage into the general population only half of methadone-associated deaths are among those people actually prescribed methadone." In other words, the 22 deaths among the addicts in the Kimber et al. study would probably have been matched by an equal number of deaths among people not included in the study, a possibility completely omitted from the analysis. This means that there might have been nearly four deaths among people not part of the study for every hundred people treated with methadone. For doctors to prescribe a drug to people in the knowledge that their prescription will kill people other than their patients is surely questionable, to say the least. It is also a matter of ethical concern to doctors whether their patients die as a result of their own conduct alone, or whether they die with the assistance of the treatment that they have recently prescribed for them. If it is not of concern, it can only be because the patients are not regarded as autonomous or self-determining human beings: a view that is not only empirically mistaken, but has sinister implications from a policy point of view.

Public health considerations are important in the field of addiction. $^{12}$ There is little evidence, however, that methadone is beneficial in this respect and controlled trials of the drug are totally irrelevant to these considerations. For example, it does not follow that if a controlled trial demonstrates that addicts prescribed methadone commit fewer crimes than those not so-prescribed, that the amount of crime committed by heroin addicts as a whole in society has decreased. Indeed it would be surprising if it did, since criminality is a better prediction of addiction than addiction is of criminality. ${ }^{13}$ In a survey I conducted in Birmingham Prison, I found that 67 per cent of newly-imprisoned heroin addicts had received a prison sentence before they had ever taken heroin. Given both the low detection rate of crimes and the rarity of imprisonment on a first offence, this suggests extensive criminal activity before and not consequent upon addiction.

In 1996, there were 84 heroin-associated deaths in Scotland ${ }^{14}$ and 74 methadone-associated ones; ${ }^{15}$ in 2010 , as we have seen, there were 254 and 174 respectively. This is despite an enormous increase in the number of prescriptions of methadone and the fact than in 1999 $60 \%-80 \%$ of the heroin addicts in Glasgow were already prescribed methadone and $41 \%-73 \%$ in Edinburgh ${ }^{16}$ (the cities where most Scottish addicts live). In other words (and at the very least) the widespread prescription of methadone is compatible with an increase both in the prevalence of heroin addiction and in the number of drugassociated deaths irrespective of whether or not controlled trials of methadone show benefits to individual addicts. Indeed, these figures add further evidence that the disease model of opiate addiction is mistaken.

Among the most important public health benefits of methadone prescription should be a) a reduction in the number of opiate-associated deaths, and b) a reduction in the prevalence of addiction in the first place. Neither of these benefits has accrued and one could argue that the reverse has happened. Attempts to show that the rate of methadone-associated deaths per prescription 
has decreased with the use of strategies such as supervised consumption is irrelevant from the point of view of public health, unless it can be shown that there is an overall benefit to the population as a whole. ${ }^{15}$ The policy of prescribing methadone for heroin addiction resembles a dog chasing its own tail.

The evidence concerning the effect, if any, of methadone prescribing upon the prevalence of blood-borne viruses is likewise equivocal. For example, by 201057 per cent of Scottish injecting addicts were hepatitis $C$ positive (47 per cent in England, Wales and Northern Ireland). Furthermore, 'current levels of hepatitis $C$ transmission among [intravenous drug abusers] appears to be higher than a decade ago'. ${ }^{17}$ In Scotland, the total number of IV drug-abusers newly diagnosed with HIV has not changed in a decade. ${ }^{17}$ Perhaps this is not very surprising, since methadone, while it reduces the level of intravenous drug abuse in individuals, does not altogether stop it and it remains quite common for people who are prescribed methadone to be vectors of blood-borne viruses. For example, of the 302 addicts in the Kimber et al. study who were still receiving opiate substitution therapy at the end of the study, II2 (37 per cent) were still injecting; indeed, 83 per cent of all the people injecting at the end of the study period were prescribed methadone. ${ }^{9}$ For a large proportion of the patients, then, opiate substitution therapy is a misnomer: it is opiate adjunct therapy. But even the word therapy here is of doubtful application.

In summary, methadone treatment is philosophically ill conceived, ethically dubious, clinically of equivocal benefit, and from the public health point of view, worthless at best and costly at worst.

\section{REFERENCES}

I Ministry of Health (Great Britain), Scottish Home and Health Department. Drug addiction: the second report of the Interdepartmental Committee, 3 I July 1964. London: HMSO; 1965.

2 NHS Treatment Agency for Substance Misuse. National and regional estimates of the prevalence of opiate and/or crack cocaine use 2009-10: a summary of key findings [Internet]. London:The National Treatment Agency for Substance Misuse; 20II [cited 20I2 April 25]. Available from: http://www.nta.nhs.uk/uploads/prevalencesummary0910.pdf

3 Robins LN. The Sixth Thomas James Okey Memorial Lecture. Vietnam veterans' rapid recovery from heroin addiction: a fluke or normal expectation? Addiction 1993; 8:104I-54. http://dx.doi. org/I0.1 III/j.1360-0443.1993.tb02 I23.x

4 Fingarette H. Heavy drinking: the myth of alcoholism as a disease. California: University of California Press; 1989.

5 Husack DN. Drugs and rights. Cambridge: Cambridge University Press; 1992.

6 Davies JB. The myth of addiction. An application of the psychological theory of attribution to illicit drug use. Switzerland: Harwood Academic Publishers; 1992.

7 Robins LN, Helzer JE, Davis DH. Narcotic use in Southeast Asia and afterward. An interview study of 898 Vietnam returnees. Arch Gen Psychiatry 1975; 32:955-6I. http://dx.doi.org/l0.100I/ archpsyc.1975.0176026001900I

8 McKeganey N. Controversies in drug policy and practice. Basingstoke: Palgrave Macmillan; 20I I.

9 Kimber J, Copeland L, Hickman M et al. Survival and cessation in injecting drug users: prospective observational study of outcomes and effect of opiate substitution treatment. BMJ 2010;34I:c3172. http://dx.doi.org//0.I I36/bmj.c3 I 72 